DOI: $10.20287 /$ ec.n27.v2.a07

\title{
O xadrez enquanto narrativa ficcional
}

\author{
Diniz Cayolla Ribeiro \\ I2ADS, Faculdade de Belas Artes do Porto \\ E-mail: dribeiro@fba.up.pt
}

\begin{abstract}
O xadrez é seguramente um dos jogos de tabuleiro mais valorizados e estudados no mundo contemporâneo. São inúmeros os estudos, as monografias e os artigos especializados que esmiúçam as diferentes fases das partidas de xadrez - abertura, meio-jogo, final -, procurando compreender as grandes ideias estratégicas e/ou as possibilidades táticas que atravessam as distintas partes do jogo. Existem, porém, outras facetas menos conhecidas ou mesmo inexploradas. O lado ficcional é uma delas. À semelhança de uma história apelativa, o xadrez também tem uma estrutura narrativa, recheada de plot points

história bem caracterizada, o xadrez também tem várias personagens que se movimentam nos tabuleiros, se enfrentam, e por vezes se matam. À semelhança de uma história atual, o xadrez também espelha os temas humanos, as suas ideologias, ou mesmo o zeitgeist de uma época. O presente texto visa revelar essa outra faceta ficcional do xadrez menos conhecida, contribuindo deste modo para enriquecer o nosso olhar sobre esse jogo milenar, bem como para demonstrar que as partidas de xadrez poderão servir de suporte para intrigantes e fascinantes histórias, umas vezes cómicas, outras vezes trágicas.
\end{abstract} e de volte-faces imprevisíveis. À semelhança de uma

Keywords: narrativa; guião; xadrez; cognição; heurística.

\section{Abertura}

$\mathrm{O}$ xadrez é seguramente um dos jogos de tabuleiro mais conhecidos, praticados e respeitados no mundo inteiro. Mesmo aqueles que não o sabem jogar associam-no imediatamente a combates estratégicos e compreendem que o mesmo possa ser usado nos média como metáfora para outros embates mais simbólicos. Quem não se lembra, por exemplo, do célebre duelo em 1972, em plena Guerra Fria, no qual o challenger norte-americano Robert (Bobby) Fischer desafiou e derrotou o representante do bloco soviético Boris Spassky, que na altura detinha o cetro de campeão do mundo? Ou então do não menos famoso embate na década de 80 entre Anatoly Karpov e Garry Kasparov? Ou ainda do confronto titânico entre o ser humano e a máquina, em

Data de submissão: 2017-11-19. Data de aprovação: 2018-07-18.

A Revista Estudos em Comunicação é financiada por Fundos FEDER através do Programa Operacional Factores de Competitividade - COMPETE e por Fundos Nacionais através da FCT - Fundação para a Ciência e a Tecnologia no âmbito do projeto Comunicação, Filosofia e Humanidades (LabCom.IFP) UID/CCI/00661/2013.
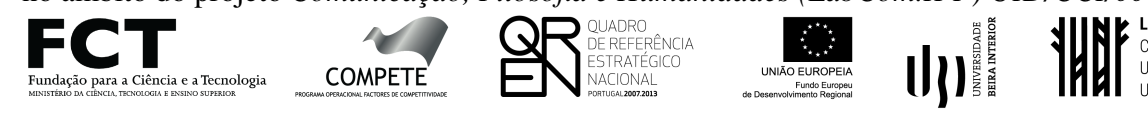

LABCOM.IFP COMUNICACC̃OO, FILOSOFIA E HUMANIDADES
UNIDADE DE INVESTIGACÃAO UNIVERSIDADE DA BEIRA INTERIOR 
1996 e 1997, que opôs o mesmo Garry Kasparov ao supercomputador Deep Blue, e que acabou com a derrota do nosso representante?

Noutros termos, o xadrez é um jogo que extravasa largamente o tabuleiro em que é praticado, e não é por isso de estranhar que as mais diversas áreas, mais ou menos académicas, o tenham usado ao longo dos tempos como meio de investigação. Encontramo-lo no campo da psicologia, desde pelo menos finais do século XIX, como cobaia, ou mosca do vinagre (como por vezes jocosamente se diz no âmbito da inteligência artificial), para testar hipóteses de carácter cognitivo (cf. Binet, 1894; Simon e Chase, 1973; Groot, 1978). Encontramo-lo em várias monografias mais recentes ligadas à economia e à gestão, nas quais o xadrez é usado como modelo estratégico e tático para outras guerras a serem travadas nos tabuleiros negociais e empresariais (cf. Pandolfini, 2003; Rice, 2008; Illescas, 2012). E encontramo-lo noutros trabalhos mais desportivos, que relacionam por exemplo o xadrez com o futebol e que procuram mostrar que estes dois jogos, apesar de parecerem tão distintos, partilham elementos estruturais semelhantes. Continuando com as palavras de Adam Wells, autor do livro Football and Chess: Tactics Strategy Beauty:

A relação entre xadrez e futebol não é uma ideia obscura que vem à mente enquanto assistimos a certos tipos de jogos futebol. É uma parte intrínseca de todos os jogos de futebol, sejam eles fechados e lentos ou vivos e abertos. Ao extrairmos dos jogos os seus componentes estruturais mais básicos, podemos descobrir quão reais e extensas são essas semelhanças. Isso, por sua vez, pode oferecer-nos alguma explicação sobre o porquê dos jogos serem esteticamente agradáveis e significativos para muitos adeptos $(2007, \text { p. } 5)^{1}$.

É neste contexto algo especulativo, mas também criativo e altamente heurístico, que se situa o presente estudo. Mais concretamente, ao longo das próximas páginas procurar-se-á demostrar que existem pelo menos cinco pontos em comum entre o xadrez e a escrita cinematográfica, argumentando-se deste modo que as narrativas xadrezísticas poderão servir como base para empolgantes histórias ficcionais. Centremos então o foco da nossa atenção no campo da narrativa, média e cognição e analisemos de que modo esta articulação entre o xadrez e a ficção poderá ser posta em prática, ou pelo menos esboçada, para ulteriores desenvolvimentos.

\section{MEIO-JOGO}

\section{Conflito}

Apesar de existirem inúmeros livros distintos (Field, 1979; Mckee, 1997; Vogler, 2006; Truby, 2007; só para citar alguns) sobre a forma como se deve escrever um guião cinematográfico, há pelo menos um ponto em que todos os autores estão de acordo: uma história bem contada tem de ter conflito. É a partir dele que tudo o resto acontece. E o mesmo se passa ao nível do jogo de xadrez. O conflito entre as brancas e as negras existe desde o primeiro momento tanto ao nível

1. Tradução livre. No original "The relationship between chess and football is not an obscure idea that comes to mind whilst watching certain types of football. It is a permanently entrenched part of all football games, whether they are tight and slow or lively and open. By stripping the games down to their most basic structural components, we can find out just how real and extensive these similarities are. This may in turn offer us some explanation as to why the games are aesthetically pleasing and meaningful to so many (2007, p. 5). 
macro, em que cada um dos jogadores procura derrotar o adversário, como ao nível micro, no qual as peças disputam entre si o controle das casas do tabuleiro. Dito por outras palavras, o xadrez transpira conflito por todos os poros, e tal como lembrava Kasparov num manual de iniciação ao xadrez, quanto maior forem as capacidades do jogador para "reconhecer estes pequenos conflitos que surgem com frequência ao longo do jogo, tanto melhor ele saberá avaliar as consequências e correspondentemente tomar as melhores decisões" (1998, p. 14).

Como já se percebeu pelos exemplos atrás expostos, o xadrez é um meio ideal para simbolizar grandes conflitos - "guerra fria", passado e presente, homem vs. máquina - ainda que também possa ser usado para representar outras guerras menos prosaicas ou até mais abstratas. O livro Chess Masterpieces: One Thousand Years of Extraordinary Chess Sets (Dean, Brady, and Kasparov, 2010) mostra-nos como, através de diferentes conjuntos de peças recolhidas um pouco por todo o mundo: Colonizadores vs. Nativos, Cowboys vs. Índios, Cristãos vs. Muçulmanos, Cruzados vs. Mouros, Europeus vs. Africanos. E apresenta-nos ainda outros tabuleiros em que, por exemplo, a Virtude enfrenta o Vício, o Bem luta contra o Mal, ou o Dia acareia a Noite.

Independentemente do conflito em causa, o aspeto mais importante a reter é que ambos os lados se confrontam com armas absolutamente idênticas. No xadrez (assim como noutros jogos de tabuleiro, convém lembrar), a simetria é total, algo que poderá passar despercebido uma vez que não acontece em muitas outras modalidades. No futebol, por exemplo, apesar de ambos os lados se defrontarem com o mesmo número de jogadores, a qualidade desses jogadores varia. $\mathrm{O}$ mesmo se passa no basquetebol, ou no andebol, ou em qualquer outra modalidade desportiva de grupo. A quantidade é a mesma, mas a qualidade varia. No xadrez isso não acontece. No xadrez, ambos os lados jogam com um conjunto de peças rigorosamente igual. A simetria é absoluta.

Este pequeno pormenor é relevante porque nos lembra que para haver uma luta justa deverá existir um equilíbrio entre ambas as partes. Ou seja, tal como ocorre em muitas histórias empolgantes, no xadrez o herói e o vilão enfrentam-se com as mesmas armas. O modo como cada um as vai usar é que faz toda a diferença. E, à semelhança uma vez mais dessas histórias que nos prendem ao ecrã, o conflito entre ambas as partes envolvidas ocorre, como já foi referido, ao longo de toda a narrativa, em cada cena, e não apenas a um nível mais geral. A premiada série televisiva norte-americana 24 (Fox, 2001-2010) poderá ser vista como um extraordinário exemplo deste tipo de tensão permanente.

Em suma, histórias bem construídas e partidas de xadrez partilham a mesma base: o conflito. A tensão é constante; cada avanço na narrativa é disputado e conquistado. A transposição deste conflito contínuo que acompanha uma partida de xadrez para um guião cinematográfico poderá originar histórias empolgantes que nos deixem agarrados ao ecrã do princípio ao fim da história.

\section{Estrutura narrativa}

O facto de todos os lances conterem tensão e conflito não significa que não existam momentos do jogo distintos, diferentes, que sobressaiam de todos os outros. Isto é, o facto de o conflito ser constante ao longo da partida de xadrez não significa que não possa haver momentos de viragem, ou plot points como vulgarmente se diz no mundo da escrita cinematográfica (Field, 1979, 1984). Pelo contrário, à semelhança de uma história paradigmática, também no xadrez existem dois mo- 
mentos principais que fazem a transição entre os atos, assim como outros pequenos beliscões (pinches) que fazem a história avançar.

Nas narrativas cinematográficas temos o primeiro ato, ou setup, no qual as personagens principais são apresentadas e introduzido o problema que irá originar a intriga (Field, 1979). No xadrez temos a abertura, que corresponde ao momento em que ambos os jogadores desenvolvem as suas peças, lutam pelo centro do tabuleiro, e procuram colocar o seu rei em segurança. As semelhanças entre ambas as situações emergem imediatamente. Tal como na primeira parte das histórias em três atos, também na abertura de xadrez começa-se por apresentar os "personagens" e deixa-se as contendas maiores para mais tarde. Ou seja, neste primeiro momento, o que realmente importa é conseguir colocar as peças nos locais corretos para a luta que já se avizinha. O conflito existe, está lá, mas materializa-se sobretudo na luta pelo centro do tabuleiro, bem como na tentativa de dificultar o desenvolvimento do adversário, levando-o a colocar as peças em casas menos favoráveis. E só quando a abertura fica concluída é que se passa para a segunda fase do jogo. Nessa altura, reexamina-se a posição, pensam-se nos prós e contras, e elabora-se um plano de jogo. Temos assim o primeiro plot point da partida.

A fase do meio-jogo corresponde ao segundo ato duma história paradigmática. É aqui, na tentativa de executar os seus planos, que o conflito realmente acontece, o que levará a uma luta renhida entre os dois beligerantes. É aqui que são concretizados os golpes táticos mais incisivos (foreshadowing: este assunto será retomado mais à frente) a partir de planos estratégicos mais abstratos. É aqui que os dois antagonistas irão verdadeiramente testar-se, colocando em prática um plano que tem, como sabemos, um objetivo comum: matar o adversário! Sim, porque dar xequemate ao Rei simboliza assassiná-lo, como nos lembra Ernest Jones na sua original contribuição para o estudo psicanalítico dos jogadores de xadrez, publicada originalmente em 1931.

O que nos leva ao terceiro ato: ao final da partida. Esta derradeira fase do jogo normalmente ocorre após uma série de trocas relevantes em cima do tabuleiro. Isto é, para que o final da partida surja é necessário que muitas peças tenham sido capturadas, restando apenas algumas que serão determinantes para o desfecho da "intriga". Esta simplificação da posição corresponde ao segundo plot point, dando origem ao epílogo da partida. Não será também isso que se passa no mundo das histórias? Depois dos primeiros combates, das guerras ou quezílias mais gerais entre as várias personagens, não ficamos também com a batalha final entre os dois personagens principais? Não se chama a isto clímax?

Para além do mais, nos finais das partidas de xadrez, novamente à semelhança das histórias, ocorrem por vezes transformações decisivas de personagens-chave, que conduzirão à vitória tão desejada do nosso herói. Pensemos, por exemplo, na promoção do peão, na possibilidade desta humilde peça chegar à oitava casa e se transformar numa outra peça mais forte, que na maioria das vezes é a Rainha (ou Dama, como se costuma dizer no mundo do xadrez). Ao pensar nesta promoção do peão ocorre-nos imediatamente a transformação de algumas personagens famosas da nossa ficção (Luke Skywalker, Daniel Larusso, Harry Potter), ${ }^{2}$ que, no clímax do terceiro ato,

2. Luke Skywalker, Daniel Larusso e Harry Potter são os protagonistas dos sucessos cinematográficos Star Wars (I977), The Karate Kid (1984) e Harry Potter and the Sorcerer's Stone (2001) respetivamente. 
descobrem que tinham poderes consigo, ou armas secretas, que desconheciam e que acabam por ser decisivas para a resolução da situação. "Use the force Luke. Let go!"

\section{Personagens}

E assim chegamos às peças de xadrez e à sua possibilidade de servirem de inspiração para personagens-tipo.

A ideia de criar um conjunto de personagens a partir de um conceito ou de algo preexistente não é uma novidade no mundo da escrita ficcional. Como é bem sabido, Vladimir Propp, na sua muito citada obra Morfologia do Conto (publicada originalmente em 1928), apresenta as 31 funções dos contos populares russos em sete esferas de ação, agrupadas por personagens: Agressor, Doador, Auxiliar, Princesa ou Pai, Mandador, Herói e Falso Herói. Do mesmo modo, Christopher Volger, a partir dos trabalhos de Carl Jung e Joseph Campbell, apresenta-nos no seu livro A Jornada do Escritor (cuja primeira edição é de 1992) um conjunto de personagens arquetipais, nas quais se destacam oito figuras bem conhecidas: Herói, Mentor, Guardião do limiar, Arauto, Camaleão, Sombra, Aliado e Pícaro. A pergunta que se coloca então é saber se será possível fazer algo de semelhante a partir das seis peças de xadrez.

O exemplo da promoção do peão mostra-nos que a resposta é claramente afirmativa, e poderá servir de ponto de partida para esta secção do texto, enfatizando, porém, que as associações de peças a personagens-tipo que irão ser apresentadas são apenas sugestões de muitas outras ligações possíveis. Estamos claramente a dar os primeiros passos num campo em aberto, com um enorme potencial heurístico. O fundamental aqui é explorar este manancial de possibilidades a partir da história das peças e da forma como as mesmas se movem no tabuleiro.

Regressemos então ao peão. Ao contrário daquilo que se vulgarizou dizer no senso comum, esta peça não é insignificante. É um facto que é uma peça algo limitada no seu movimento - só anda uma casa de cada vez -, mas também é verdade que o peão goza de uma série de prerrogativas que não conseguimos encontrar em mais nenhuma outra: tem dois tipos diferentes de movimento - um para avançar outro para capturar; goza da possibilidade de avançar duas casas no primeiro lance; e, como já foi referido anteriormente, é a única peça que se pode transformar numa outra.

Individualmente, o peão é a peça ideal para representar o personagem imaturo, jovem, ingénuo, que vai adquirindo poderes ao longo da história e que se acaba por transformar na peça mais poderosa, em termos efetivos, em cima do tabuleiro. Daí a referência aos protagonistas jovens de filmes célebres referidos anteriormente.

Em termos coletivos, o peão representa o povo, as multidões, a coletividade. Convém não esquecer que os planos de xadrez se fazem, na esmagadora maioria das vezes, a partir das estruturas de peões, e que a força dos peões reside precisamente na sua própria fraqueza: as outras peças temem-nos, não querem ser capturadas por eles, e por isso evitam colocar-se nas casas que são controladas pelos peões. 
Em suma, os peões são peças muito relevantes, tanto em termos individuais como coletivos "são a alma do xadrez", escreveu Philidor em $1792^{3}$-, e uma boa história deverá tê-los sempre em consideração, podendo usá-los como meio ideal para a identificação com os espectadores.

A torre, por sua vez, corresponde à retidão. As torres são peças escorreitas. Movimentam-se em linha reta na vertical ou horizontal. São peças poderosas, pesadas, que tardam quase sempre em entrar em jogo, mas quando o fazem, fazem-no com uma grande eficácia, e muitas vezes para resolver a partida. Não é por acaso que um dos finais de partida mais comuns no xadrez, e mais estudado, seja o final de torres.

As torres são também peças confiáveis, sensatas, que passam uma boa parte da partida ao lado do seu monarca, protegendo-o, mas também "aconselhando-o". Quando pensamos em Torres pensamos imediatamente em homens sábios, justos, impolutos. Pensamos em mentores. Voltando às referências cinematográficas anteriores, as Torres fazem-nos lembrar personagens como ObiWan Kenobi ou Mr. Miyagi, os famosos mentores de Star Wars e The Karate Kid, respetivamente.

Os bispos, em contrapartida, são peças que nos inspiram muito menos confiança. São peças oblíquas, que nos olham de esguelha, na diagonal. E são peças maniqueístas! Um bispo apenas vê uma cor do tabuleiro: as casas brancas ou as casas negras. Tudo o que não estiver nas diagonais da cor das suas casas passa-lhes ao lado.

Em termos caracterológicos, os bispos são os experts nas suas áreas, reputados peritos no seu campo de especialidade, mas completamente ineptos em tudo o resto. São nerds por excelência. São personagens que podem ter um papel fundamental na intriga, ajudando o herói na concretização do seu objetivo, mas completamente desastradas na vida pessoal e absolutamente incapazes de ver o outro ponto de vista.

E ao contrário do que se possa pensar à primeira vista, os bispos não têm nada que ver com a religião. Aqui e em língua inglesa chamam-se bispos, mas em França são "bobos da corte" (fou) e na Alemanha são "corredores" (Läufer). E os exemplos poderiam continuar: "Porta-estandarte" (alfiere) em italiano; "Elefante" ( $\mathrm{C} \pi \mathrm{OH}$-Slon) em Russo; e "Caçador" (Lovac) em Sérvio. Os espanhóis criaram uma palavra nova para esta peça, a partir do árabe: Alfil.

Os cavalos são peças nobres, tanto pelo facto de representarem um animal que é visto como distinto e associado às camadas aristocráticas da sociedade, como também pelo facto de simbolizarem a nobreza em cima do tabuleiro: os cavalos chamam-se knights (cavaleiros) em língua inglesa; são os Sirs de sua Majestade. A própria forma como se movimentam em cima do tabuleiro diz muito sobre o seu pedigree. O cavalo é a única peça que pode saltar por cima das outras - uma prerrogativa animal, dirão alguns, mas também aristocrática, dirão outros - e quando ataca uma peça através do seu movimento em "L" nunca pode ser atacada por essa mesma peça, a não ser que também seja um cavalo. Noblesse oblige!

Os cavalos fazem-nos lembrar outro animal, o polvo, pela forma tentacular como dominam as casas do tabuleiro. Um cavalo num posto avançado, protegido, é uma peça poderosíssima, sobretudo se a situação for complexa e muito fechada, porquanto irradia poder para todo o lado a partir duma posição inatacável. No centro do tabuleiro, domina oito casas. Os cavalos representam

3. François-André Danican Philidor (1726 - 1795) foi um compositor francês e um notável xadrezista, bem como o autor de um dos primeiros estudos sobre o xadrez intitulado Analyse du jeu des échecs (1749). 
ao nível da ficção aquelas personagens que se conseguem infiltrar em situações intricadas e exercer um enorme poder a partir de dentro, de uma forma dissimulada. Para o bem e/ou para o mal. Os cavalos podem ser extraordinários espiões no campo do inimigo, mas também insidiosos agentes infiltrados.

Por fim, temos o Rei e a Dama. Estas peças podem movimentar-se em qualquer direção horizontal, vertical, diagonal - mas com limitações diferentes. O Rei só pode andar uma casa de cada vez; a Dama pode deslocar-se o número de casas que quiser, desde que tenha o caminho livre.

Logo aqui temos uma diferença considerável que será discutida no ponto seguinte e que remete para o facto do xadrez refletir a sociedade. Por agora, importa apenas relembrar que estas peças são provavelmente as personagens mais relevantes da história. A primeira por poder ser facilmente associada a personagens simbólicas que precisam de ser protegidas a qualquer custo: monarcas, presidentes da república, figuras públicas importantes, outras personagens significantes para o herói (mulher, filha ou filho, pai, etc.). Numa história baseada no xadrez, o Rei seria uma destas personagens que terá de ser protegida dos xeques do adversário, sob pena de perder a contenda. Convém lembrar que no xadrez o ataque direto ao Rei obriga a que a jogada seguinte tenha de ser obrigatoriamente um lance que retire o monarca da ação do xeque; caso contrário é xeque-mate e o jogo está perdido.

A Dama, por sua vez, também pode ser facilmente associada ao herói ou heroína que irá resolver a partida. Já o tínhamos percebido quando falámos na promoção do peão a Dama e evocámos personagens ficcionais como Luke Skywalker ou Harry Potter. Esta peça é extremamente poderosa porquanto congrega simultaneamente o poder do bispo e da torre. A sua ação em cima do tabuleiro é absolutamente letal, ainda que precise dos restantes companheiros para dar o xeque-mate final.

E este é um aspeto que nunca deve ser esquecido. Por muito brilhante que possa ser uma peça como a Dama, precisará sempre dos outros companheiros para resolver a partida. Dito por outras palavras, o xadrez é um jogo de equipa. Num certo sentido, a Dama neste jogo faz-nos lembrar o D'Artagnan da famosa história de Alexandre Dumas, que, como também sabemos, não atuava sozinho, necessitando do brilhantismo e da bravura dos seus três colegas mosqueteiros: Athos, Aramis e Portos. "Unus pro omnibus, omnes pro uno".

\section{Sociedade}

A relação do xadrez com a sociedade já foi abordada noutros textos (Cayolla Ribeiro 2015, 2017). Ainda assim, tendo em consideração o propósito deste texto - mostrar que o xadrez poderá servir de base para a escrita ficcional - serão revisitadas aqui algumas dessas ideias principais tratadas anteriormente.

Comecemos pela questão do género.

A Dama que conhecemos hoje é uma invenção ocidental. O lugar da Dama atual era ocupado por uma espécie de conselheiro ou vizir nas versões indianas ou árabes que precederam o xadrez moderno: Mantri em Sânscrito, Farzīn em Persa, Firzān ou Firz em Árabe. Ou seja, era uma peça masculina e, pasme-se, tinha uma liberdade de movimentos inferior à do Rei: só podia movimentar-se uma casa de cada vez na diagonal! Com a entrada do xadrez no mundo medieval europeu por volta do século $\mathrm{X}$, por intermédio das invasões muçulmanas, esta peça mudou 
literalmente de género e foi adquirindo progressivamente uma maior amplitude de movimentos, acabando por se transformar na peça mais poderosa em cima do tabuleiro.

Marilyn Yalom, fascinada pela transfiguração desta peça, dedicou uma monografia à evolução da Dama, considerando-a como um "ícone do poder feminino" e correlacionando a sua ascensão com três alterações fundamentais ocorridas na Europa, entre os séculos XI-XII. Citando as suas palavras:

Durante os séculos XI e XII, quando a rainha estava expulsando o vizir do tabuleiro de xadrez europeu, havia numerosas correntes favoráveis à ideia de poder feminino. A primeira estava relacionada com as funções da rainha cristã, que tomou sua forma distinta durante o início da Idade Média. A rainha era, acima de tudo, a esposa do rei, sua fiel companheira, ajudante e súbdita leal. Como o vizir oriental, ela também era conselheira, especialmente em assuntos relacionados com o parentesco, mas mesmo em matérias de diplomacia e guerra. (...)

A maioria das rainhas, assim como duquesas e condessas, passaram a reinar em virtude do casamento com um soberano reinante e eram então conhecidas como rainhas consortes. (...) Uma segunda corrente cultural que coincidiu com o nascimento da rainha de xadrez e reforçou a instituição da rainha foi o culto da Virgem Maria. (...) Centenas de igrejas foram dedicadas a Nossa Senhora, com mãe e filho representados em esculturas, pinturas nas paredes e vitrais. (...)

Uma terceira influência foi o culto do amor romântico. A adoração da bela dama, muitas vezes a esposa de um rei ou poderoso nobre, foi celebrada pela primeira vez por trovadores no sul da França e depois exportada para todas as Cortes da Europa (2004, p. XXI-XXII). ${ }^{4}$

De facto, a transformação é impressionante e faz todo o sentido colocar a possibilidade destas alterações ocorridas no mundo medieval terem influenciado decisivamente o xadrez, mostrando deste modo que o jogo absorveu e refletiu o que se estava a passar à sua volta. No entanto, questionamo-nos: será que esta hipótese deixou de fazer sentido? Dito por outras palavras, não continua o xadrez a ser um espelho da sociedade? Não persiste em mostrar que existe uma diferença no modo como a sociedade trata a questão do género? É que, à semelhança do que ocorre no tabuleiro do jogo, também na sociedade as mulheres frequentemente se esforçam mais, trabalham mais, e detêm muitas vezes um maior poder efetivo, apesar de continuar a ser masculino o detentor

4. Tradução livre. No original "During the eleventh and twelfth centuries, when the chess queen was driving the vizier from the European board, there were numerous currents favorable to the idea of female power. The first was the reality of Christian queenship, which has taken its distinctive shape during the early Middle Ages. The queen was, first and foremost, the king's wife, his faithful partner, helpmate, and loyal subject. Like the Eastern vizier, she was also a giver of advice, especially on issues concerning kinship, but even in maters of diplomacy and warfare. (...)

Most queens, as well as duchesses and countesses, became rules by virtue of marriage to a reigning sovereign and were then known as queens consort. (...)

A second cultural current that coincided with the chess queen's birth and reinforced the institution of queenship was the cult of Virgin Mary. (...)

Hundreds of churches were dedicated to Our Lady, with mother and child represented in sculpture, wall paintings, and stained glass. (...)

A third influence was the cult of romantic love. The adoration of beautiful lady, often the wife of a king or powerful noble, was first celebrated by troubadours in the South of France and then exported to all the courts of Europe (2004, p. XXI-XXII) 
do cetro do poder simbólico. É que sem Rei não há xadrez; o seu poder é absoluto. A Dama é uma peça muito poderosa, mas em última instância poderá ser sacrificada para salvar o seu monarca.

Existe também uma diferença significativa ao nível da cor das peças, isto é, "racial". Tal como foi escrito anteriormente, no xadrez a simetria é total. Contudo, existe uma regra introduzida pelos humanos que mancha esta simetria utópica: as brancas fazem o primeiro lance. Este pequeno pormenor pode parecer insignificante (ideológico?), mas faz toda a diferença. Na prática, significa que existem mais 7 a 10\% de hipóteses das brancas vencerem o jogo: depende da base de dados analisada. ${ }^{5}$ E esta diferença aumenta à medida que filtramos os jogos, ficando apenas com aqueles que são jogados ao mais alto nível. Aqui a diferença pode chegar aos $20 \%$, ou mesmo ultrapassála. A título de exemplo, na final do torneio de candidatos de 2014, que reuniu os oito finalistas para apurar aquele que iria defrontar o campeão do mundo, as Brancas ganharam em $30 \%$ dos jogos e as negras em apenas $9 \%$. As restantes partidas (61\%) terminaram empatadas. ${ }^{6}$

Como já foi referido, este tópico também foi amplamente trabalhado em textos anteriores (Cayolla Ribeiro, 2009; 2010; 2015; e 2017). No presente contexto, pretende-se apenas relembrar que, uma vez mais, o xadrez está a espelhar a realidade que existe à sua volta, mostrando que existe uma profunda correlação entre as ideias que moldam as projeções humanas e as condições materiais concretas nas quais essas mesmas ideias são forjadas. Dito por outras palavras, inúmeros trabalhos académicos e artísticos pós-coloniais relembram-nos que o racismo é uma realidade contemporânea, e que alguns seres humanos, adaptando a célebre frase de Orwell, "são mais humanos do que outros". O xadrez limita-se a constatar essa diferença, o que uma vez mais poderá ser útil para contar histórias, na medida em que será capaz de usar esta assimetria como pano de fundo. Exemplo? Colocar do lado das negras os heróis que irão combater e derrotar a vantagem posicional das brancas. Chama-se a isto "Jogar de Negras" (Cayolla Ribeiro, 2009).

$\mathrm{O}$ facto de o xadrez sintomatizar os problemas de género e de "raça" que existem na nossa sociedade não significa que também não possa indiciar outras mudanças que estão a despontar à nossa volta. O xadrez 960 é um bom exemplo disso. Esta variante de xadrez foi criada por Bobby Fischer-daí que se use por vezes a expressão Fischer Random Chess - em finais do século passado e teve o seu auge na primeira década do século XXI. Basicamente, consiste numa variante de xadrez em que são aplicadas todas as regras convencionais, exceto uma: a posição inicial. Isto é, ao contrário da versão tradicional que começa sempre o jogo a partir da mesma disposição das peças - Torre, Cavalo, Bispo, Dama, Rei, Bispo, Cavalo, Torre -, no xadrez 960, como o próprio nome indica, existem 960 posições iniciais possíveis que são escolhidas aleatoriamente por um programa informático. Ou seja, o computador pode escolher, por exemplo, uma posição em que a disposição das oito peças é a seguinte: Cavalo, Torre, Rei, Torre, Bispo, Bispo, Cavalo, Dama. Ou então uma outra com a seguinte disposição: Bispo, Torre, Cavalo, Bispo, Rei, Dama, Torre, Cavalo. E assim por diante. As únicas duas condições que prevalecem são as seguintes: 1) tem de haver um bispo de casas brancas e outro de casas negras, e 2) o Rei deverá estar sempre situado entre as duas torres, para que possam ser feitos os roques grande e pequeno (que não partem das

5. Na Chessbase de 2014, com mais de 4.5 milhões de partidas de xadrez, essa diferença era de 7,5\%; no site www.chessgames.com, as brancas venciam em mais $9,9 \%$ das partidas.

6. http://candidates2014.fide.com 
posições iniciais convencionais do Rei e torres, como já se percebeu, mas cujas posições finais se mantêm, assim como todas as regras que enquadram a realização desta jogada especial de xadrez).

Como facilmente se compreende, mesmo para aqueles que não sabem jogar xadrez, esta aleatoriedade da posição inicial das peças muda tudo. Toda a teoria das aberturas de xadrez, desenvolvida ao longo de séculos, e que deu origem a uma vastíssima literatura, desaparece, mantendo-se apenas os princípios gerais que governam todas as partidas de xadrez. Num ápice, todo o vasto conhecimento teórico, que poderá dar uma vantagem decisiva a todos aqueles que o dominam, evapora-se, restando apenas uma posição aleatória, de 960 possíveis, que não foi seguramente estudada, escalpelizada e memorizada até à exaustão.

Quando foi realizada a pesquisa para este texto, podia-se encontrar na internet ${ }^{7}$ um vídeo publicitário de uma conhecida cerveja que usava o xadrez 960 como base para uma analogia: vários amigos jogavam basquetebol numa cadeira de rodas para ficarem ao nível de um deles, que tinha obrigatoriamente de se deslocar dessa forma; a ideia era mostrar que aquela forma de jogar se assemelhava ao xadrez 960; não havia a vantagem inicial de se conhecer a teoria das aberturas: estavam todos no mesmo patamar.

Talvez possamos dar um passo em frente e retirar uma ideia ainda mais potente desta variante escaquística. O que o xadrez 960 nos mostra é que não existe uma forma única de olhar a realidade, ou de jogar no "tabuleiro da vida", mas sim uma pluralidade delas. Dito por outras palavras, não somos obrigados a jogar no tabuleiro societal a partir da posição inicial standard que beneficia as classes dominantes. Podemos jogá-lo a partir de "outras" posições, tirando deste modo partido daquilo que somos, independentemente de estarmos numa cadeira de rodas, sermos gays, transsexuais, negros, canhotos, ou de ter outros traços identitários que nos possam subalternizar. O importante é jogar, tendo a possibilidade de o fazer com as mesmas armas.

Paradoxalmente (ou talvez não), o xadrez 960 tem perdido simpatizantes nos últimos anos. Está a tornar-se cada vez mais difícil encontrar adeptos desta variante nos sites mais conhecidos de xadrez. Será um sinal dos tempos? Será que o xadrez 960 foi apenas uma moda passageira? Ou estará uma vez mais a espelhar o regresso em inúmeros países ocidentais a velhas políticas racistas, xenófobas, e com pouca consideração pela diversidade?

\section{Temas}

Resta-nos falar sobre a relação possível entre o xadrez e os temas típicos das histórias ficcionais.

No xadrez, para além das aberturas e dos finais, existem outros dois assuntos, transversais a todos os momentos da partida, que têm sido amplamente estudados, dando origem a uma vastíssima literatura sobre o tema: a tática e a estratégia. A tática diz respeito às inúmeras situações que ocorrem ao longo do jogo nas quais é possível, através de uma pequena combinação, obter uma vantagem material ou até mesmo dar xeque-mate ao rei do adversário. A estratégia, por sua vez, está relacionada com os planos mais longos que são pensados durante o jogo e que servem de pano de fundo para a colocação e movimentação das peças. Digamos que a primeira, a tática, é

7. https://chessrex.com/blog/?p=994 
mais imediatista, está mais relacionada com o tempo curto, enquanto que a segunda, a estratégia, remete para o tempo longo.

Existem inúmeros temas táticos e estratégicos no xadrez. O tópico é vastíssimo e tem um valor heurístico enorme em termos narrativos. Tendo em consideração o caráter experimental deste texto, serão apresentados três exemplos ilustrativos de situações que ocorrem frequentemente em cima do tabuleiro e que poderão servir para a criação de situações ficcionais.

Quando uma peça ataca duas peças em simultâneo, levando a que o adversário seja obrigado a perder uma delas, estamos na presença de um "garfo" ou "forqueta", como se diz na gíria xadrezística. Esta situação é recorrente. Por exemplo, é comum um cavalo atacar simultaneamente o Rei e outra peça do adversário, levando à captura dessa peça no lance seguinte. Nas histórias ficcionais também são frequentes situações em que uma personagem afeta simultaneamente outras duas, fazendo com que uma delas perca em relação à outra. As triangulações amorosas podem ser vistas como exemplos típicos deste tipo de forquetas.

Uma outra situação comum no xadrez é a "peça cravada". Significa que uma dada peça não se pode mexer, sob pena de colocar em risco uma outra peça mais relevante, e que muitas vezes poderá ser o próprio Rei. Também nas histórias ficcionais esta situação ocorre com frequência. Chama-se a isto chantagem. Ou seja, imaginando uma possível aplicação desta ideia, sempre que uma peça fosse cravada numa partida de xadrez poderia servir de mote para a criação de uma situação dramática em que uma das personagens é chantageada, o que depois seria explorada de forma criativa

Por último, temos uma situação que ocorre por vezes em cima do tabuleiro e que se chama zugzwang. É uma expressão alemã que significa que o jogador é obrigado a fazer uma jogada que o prejudicará. Noutros termos, o jogador não tem alternativa: é obrigado a jogar, mesmo sabendo que irá piorar a sua situação. Também aqui encontramos inúmeras situações dramáticas nas histórias em que o protagonista tem de tomar uma decisão, sabendo de antemão que não há uma boa alternativa. Faça o que fizer, fará mal. E também sabemos que o público adora estes momentos. Chamam-se dilemas morais e são fundamentais para definir o carácter da personagem.

\section{FINAL}

Façamos então uma recapitulação de tudo o que foi exposto anteriormente, salientando os cinco pontos comuns existentes entre o "Jogo dos Reis" e as narrativas ficcionais.

Em primeiro lugar, vimos que tanto o xadrez como a ficção partilhavam um mesmo interesse pelo conflito e que a tensão permanente que se vive ao longo de uma partida poderá servir de base para a construção de inúmeras cenas ficcionais. Em segundo lugar, percebemos que existe uma estrutura narrativa comum dividida em três atos, com dois plot points principais a fazerem a transição entre as partes. Verificamos igualmente que a diversidade e versatilidade das peças de xadrez poderá servir de guia para a construção de personagens-tipo, ou arquetipais como outros lhes chamaram, o que não retira qualquer tipo de densidade às mesmas, apenas as complexifica. Em quarto lugar, vimos que o xadrez espelha o zeitgeist duma época histórica, materializando as assimetrias de "raça" e género (entre muitas outras) que ocorrem nas nossas sociedades, podendo deste modo 
servir de mote para histórias ficcionais. Por último, observamos que o xadrez é por excelência um jogo estratégico e tático, originando inúmeras situações que podem ser dramatizadas.

Tudo isto foi dito, demonstrado e exemplificado ao longo das páginas anteriores. O passo seguinte consistirá em colocar este paralelismo em prática. Como fazê-lo? Como transformar estas ideias em algo concretizável? Como transpor para o tabuleiro ficcional os dramas que estão permanentemente a ocorrer nas partidas de xadrez?

Estas são as perguntas que emergem neste momento e que servirão de ponto de partida para ulteriores desenvolvimentos, que tanto poderão ocorrer ao nível académico como ao nível ficcional. Para o efeito será necessário passar à prática e encontrar uma forma operativa de transformar estes pontos comuns em algo que possa servir de motor para histórias ficcionais. Ou, para tirarmos desde já partido desta analogia, será preciso que nos próximos episódios desta saga este peão encontre uma forma de alcançar a oitava casa para se poder transformar numa Dama. A ver vamos se será capaz.

\section{To be continued...}

\section{BIBLIOGRAFIA}

Cayolla Ribeiro, D. (2009). Jogar de Negras: contribuição para a discussão do(s) primitivismo(s) na arte em Portugal. Tese de doutoramento (texto policopiado), Faculdade de Belas Artes da Universidade do Porto.

Cayolla Ribeiro, D. (2010). A estratégia primitivista. Trabalhos de Antropologia e Etnologia, L, 167-177.

Cayolla Ribeiro, D. (2014). Duchamp, Chess, and the Oedipus Complex. Analyses of Cultural Productions: Papers of the 30th Conference of Psyart - Porto, 2013 (pp. 255-263). Porto: I2ADS.

Cayolla Ribeiro, D. (2015). O Xadrez como metáfora para pensar a crise nas humanidades. Revista de História da Arte (12 - Crise), 203-215.

Cayolla Ribeiro, D. (2017). Duchamp e o xadrez como ferramenta heurística para pensar o político. In J. P. Cachopo, E. Marques, F. Pinto \& E. P. Almeida (eds.), Estética e Política entre as Artes (pp. 173-190). Lisboa: Edições 70.

Chase, W. G. \& Simon, H. A. (1973). Perception in Chess. Cognitive Psychology, 4(1), 55-81.

de Groot, A. (1978). Thought and Choice in Chess. The Hague, Paris, New York: Mouton Publishers.

Dean, G.; Brady, M. \& Kasparov, G. (2010). Chess Masterpieces: One Thousand Years of Extraordinary Chess Sets. Abrams.

Field, S. (1979). Screenplay : the foundations of screenwriting. New York: Dell Pub. Co.

Field, S. (1984). The screenwriter's workbook. New York, N.Y.: Dell Pub. Co.

Illescas, M. (2012). Jaque Mate: Estrategias ganadoras del ajedrez para aplicar a tu negocio. Alienta: Barcelona. 
Jones, E. (1931). The Problem of Paul Morphy: A contribution to the Psycho-Analysis of Chess. The International Journal of Psycho-Analysis, XII (January 1931). Retrieved from www.edoc hess.ca/batgirl/Jones.html

Kasparov, G. (1988). Iniciação do xadrez (Trad. de M. Morgado,). Lisboa: Editorial Presença.

Pandolfini, B. (2003). Every move must have a purpose : strategies from chess for business and life. New York: Hyperion.

Rice, B. (2008). Three moves ahead: what chess can teach you about business (even if you've never played). San Francisco: Jossey-Bass.

Truby, J. (2007). The Anatomy of Story: 22 Steps to Becoming a Master Storyteller. New York: Farrar, Straus and Giroux.

Wells, A. (2007). Football and Chess: Tactics Strategy Beauty. Devon: Hardinge Simpole.

Yalom, M. (2004). Birth of the Chess Queen: A History. New York: HarperCollins. 